\title{
Endoparasitic Prevalence of Urban Free Ranging Bonnet macaques (Macaca radiata) in Coonoor Town, Nilgiris, Tamil Nadu: A Transversal Study
}

Manick Sundar B, Boon Allwin ${ }^{*}$, Stalin Vedamanickam, Anjana Mohanraj and Bharath Jothi S

Madras Veterinary College, TANUVAS, Chennai, Tamil Nadu, India

*Corresponding author: Boon Allwin, Madras Veterinary College, TANUVAS, Chennai, Tamil Nadu, India, Tel: 0442538 1506; E-mail: boonallwin@gmail.com

Received date: Sept 13, 2016; Accepted date: Oct 27, 2016; Published date: Oct 31, 2016

Copyright: ( 2016 Sundar MB, et al. This is an open-access article distributed under the terms of the Creative Commons Attribution License, which permits unrestricted use, distribution, and reproduction in any medium, provided the original author and source are credited.

\begin{abstract}
Bonnet macaque (Macaca radiata) is an endemic to southern India. The species that is largely arboreal is at present found in the all types of habitat, especially those created and maintained by human beings. Bonnet macaques of late have totally shifted their activity and existence towards human habitations, in other words these animals have become urban pests creating a lot of menace in human activities. This paper aims at finding out the prevalence of endoparasites in urban free ranging population of Bonnet macaques. As they share the same interface for their daily existence a zoonotic threat may be foreseen. So, a clear picture of the endoparasitic fauna of Bonnet macaques sharing the human occupations may be useful in bringing about discrete conclusions. The species encountered in the study were Ascaris sp., Trichuris sp., Strongyloides sp. and mixed endoparasitic infections consisting of Trichuris sp. with Ascaris sp. or Strongyloides sp. with Trichuris sp. Interestingly statistically no significant variations were found between the three regions where it was sampled from, the conclusion being that parasitism existed at the same level in all the three regions. The findings are discussed.
\end{abstract}

Keywords: Bonnet macaque, Endoparasites; Urban free ranging

\section{Introduction}

Bonnet macaque (Macaca radiata) is an endemic to southern India. The species that is largely arboreal is at present found in the all types of habitat, especially those created and maintained by human beings. The estimated population size of the macaque is around 170,000 in just the four southern states, of which Tamil Nadu is known to be home to about 16,000 individuals [1]. Bonnet macaques of late have totally shifted their activity and existence towards human habitations, in other words these animals have become urban pests creating a lot of menace in human activities. An interesting phrase has been coined for the purpose of better understanding in this paper free ranging urban Bonnet macaques as they are almost in coinciding proximities with the human settlements spread all over the southern part of India. Numerous birth control programs have had no effect on the population regulation. Each troop typically consists of one to several adult males and females and a variable number of sub-adults, juveniles and babies (infants) of both sexes. Similarly the ratio of different agesex classes within troops shows some variation across ecological habitats [2,3]; Understanding the life-cycle of the parasites and for understanding the spread of parasites both within and between social groups and to individuals of other species, including humans, are most important. In this study, end parasitic prevalence in urban free ranging Bonnet macaques was focused. High levels of parasitism in the animals could be attributed to abnormal high densities, cross-species, transmission and stress due to varying meteorology. Generally fighting, dominance and intra specific aggression are the factors exacerbate parasitic infections to the point of even causing death. Increased level of parasitism in Bonnet macaques may cause severe stress and the other thread being a zoonotic nidus. Outcome of this study in Bonnet macaques will yield information about the common parasites among the urban free ranging populations.

\section{Materials and Methods}

The study area was carried out in Coonoor a hill station in the Nilgiris, Western Ghats located at $11^{\circ} 21^{\prime} \mathrm{N} 76^{\circ} 49^{\prime} \mathrm{E} / 11.35^{\circ} \mathrm{N} 76.82^{\circ} \mathrm{E}$. It has an average elevation of 1850 metres ( 6070 feet) where there is distribution of Bonnet macaques during the year 2014. The faecal samples were collected from three different varied density areas, namely tourist spots (closely adjoining forest areas), parks and close to shops near the tourist spots.

The fecal samples were processed by both floatation technique and centrifugal sedimentation technique as described by Soulsby [4].

\section{Floatation technique}

Fecal sample weighing about 2 gram was taken in a $100 \mathrm{ml}$ beaker and was thoroughly emulsified with about 10 to $15 \mathrm{ml}$ of saturated sodium chloride solution. The mixture was strained through a strainer into a cup and transferred into a floatation tube till the mixture reached the brim of the tube and formed the meniscus and it was kept undisturbed for 15 to 20 minutes. A clean cover slip was taken and tip of the positive - meniscus was gently touched and then the cover slip was placed on a slide and the slide was examined under both low and high power objectives.

\section{Centrifugal sedimentation technique}

Fecal material weighing about 2 gram was taken in a $100 \mathrm{ml}$ beaker and was thoroughly emulsified with 10 to $15 \mathrm{ml}$ of water. The mixture was strained through a strainer into a cup and was transferred into a centrifuge tube as described for centrifugal sedimentation technique.

The centrifuge tubes were placed in a balanced state and centrifuged for 5 minutes at $3000 \mathrm{rpm}$ and discarded the supernatant portion in a careful manner. Using a Pasteur pipette and bulb, small amount of top layer of sediment was transferred to a clean microscopic glass slide and 
Citation: Sundar MB, Allwin B, Vedamanickam S, Mohanraj A, Jothi BS (2016) Endoparasitic Prevalence of Urban Free Ranging Bonnet macaques (Macaca radiata) in Coonoor Town, Nilgiris, Tamil Nadu: A Transversal Study. J Bacteriol Parasitol 7: 293. doi: $10.4172 / 2155-9597.1000293$

Page 2 of 3

a cover slip was placed on the drop of sediment and the slide was examined microscopically under low and high power objectives.

\section{Results}

In the summer season Trichuris sp. and Strongyloides sp+ Trichuris sp. showed highest prevalence in the tourist spots, whereas in parks and close to shops Trichuris sp. showed highest prevalence. In the winter season Trichuris sp. showed region wise prevalence percent is represented in Table 1 . Highest prevalence all the three regions. In the rainy season Strongyloides sp. showed highest prevalence in all the three regions.

\begin{tabular}{|c|c|c|c|c|c|}
\hline Summer & & Tourist spots & Parks & Close to Shops & Chi Square tests \\
\hline & Ascaris sp. & $4(13.33 \%)$ & $5(17.86 \%)$ & $5(15.15 \%)$ & \multirow[t]{17}{*}{$0.39 \mathrm{NS}$} \\
\hline & Trichuris sp. & $9(30.00 \%)$ & $16(57.14 \%)$ & $17(51.52 \%)$ & \\
\hline & Strongyloides sp. & $8(26.67 \%)$ & $3(10.71 \%)$ & $7(21.21 \%)$ & \\
\hline & Strongyloides sp. + Trichuris sp. & $9(30.00 \%)$ & $4(14.29 \%)$ & $4(12.12 \%)$ & \\
\hline & Total & 30 & 28 & 33 & \\
\hline \multirow[t]{6}{*}{ Winter season } & & Tourist spots & Park & Close to Shops & \\
\hline & Ascaris sp. & $5(20.83 \%)$ & $4(14.81 \%)$ & $6(18.75 \%)$ & \\
\hline & Trichuris sp. & $9(37.50 \%)$ & $11(40.74 \%)$ & $12(37.50 \%)$ & \\
\hline & Strongyloides sp. & $6(25.00 \%)$ & $7(25.93 \%)$ & $8(25.00 \%)$ & \\
\hline & Strongyloides sp. + Trichuris sp. & $4(16.67 \%)$ & $5(18.52 \%)$ & $6(18.75 \%)$ & \\
\hline & Total & 24 & 27 & 32 & \\
\hline \multirow[t]{6}{*}{ Rainy season } & & Tourist spots & Parks & Close to Shops & \\
\hline & Ascaris sp. & $3(18.75 \%)$ & $2(11.76 \%)$ & $3(14.30 \%)$ & \\
\hline & Trichuris sp. & $4(25.00 \%)$ & $5(29.41 \%)$ & $4(19.05 \%)$ & \\
\hline & Strongyloides sp. & $5(31.25 \%)$ & $6(35.30 \%)$ & $8(38.07 \%)$ & \\
\hline & Strongyloides sp. + Trichuris sp. & $4(25.00 \%)$ & $4(23.53 \%)$ & $6(28.58 \%)$ & \\
\hline & Total & 16 & 17 & 21 & \\
\hline
\end{tabular}

Table 1: Season-wise parasitic prevalence.

\section{Discussion}

The overall endoparasitic prevalence in case of Bonnet macaques in human inhabitations, like parks, tourist spots and close to roadside shops was in agreement with the reports furnished by Wallach and Boever [5], who opined that parasitism was the most common primate infection disease that would confront the clinicians and the nematodes made up the largest percentage of the internal parasites encountered in non-human primates.

The existing types of free ranging habits with close proximity with humans, variations in the susceptibility of primates to parasitic infections, individual body status, varying pathogenicity of different endoparasitic fauna etc. might be the reasons that could be attributed to the occurrence of endoparasitic prevalence, as encountered during this study in Bonnet macaques. In this context, it becomes noteworthy to mention the report presented by Fowler [6], who opined that the number of species of helminths as well as protozoa interfering the nonhuman primates, far exceeded the number of host species and that coexistence of many species like nilgiri langurs, common langurs in this landscape attributed to the host range of many parasites that were found in the natural state. Encountering the different helminthic fauna in the Bonnet macaques was in agreement with the report furnished by Lim et al. [7], who quoted that the majority of animals examined during the study comprising of felines, primates and hoofed mammals were found infected with at least one intestinal parasite species.

The present study revealed the occurrence of various helminthic fauna like Ascaris sp., Trichuris sp., Strongyloides sp., Strongyles and mixed endoparasitic infections comprising of any two of these, in general. The findings of various endoparasities in the free ranging macaques in urban areas in this study were in agreement with the report furnished by Varadharajan and Pythal [8]. In Bonnet macaques, Trichuris sp. was the predominantly prevalent endoparasitic fauna noticed in the Bonnet macaques. However, with regard to prevalence of different endoparasitic fauna encountered in this study variations in the response of different parasitic fauna to the climatic differences in these regions and variations in the response of the Bonnet macaques to the preference in their diet patterns, eating almost everything that is available within the human zones and drastic change of their diets to their wild counterparts. 
Citation: Sundar MB, Allwin B, Vedamanickam S, Mohanraj A, Jothi BS (2016) Endoparasitic Prevalence of Urban Free Ranging Bonnet macaques (Macaca radiata) in Coonoor Town, Nilgiris, Tamil Nadu: A Transversal Study. J Bacteriol Parasitol 7: 293. doi: $10.4172 / 2155-9597.1000293$

Page 3 of 3

Fowler in 1986 stressed the importance of zoonotically important endoparasities of non-human primates like Trichuris sp [6]. The prevalence of Strongyloides sp. in fecal samples obtained from Bonnet macaques as study was in agreement with the findings made by Raman et al. [9], who encountered moderately heavy infection of Strongyloides sp. among the macaques and attributed their occurrence to the environmental factors, in addition to the complicated parthenogenic life cycle pattern of the parasitic nematode as well as the existence of wide host range. Further, in this regard, encountering of Strongyloides fuelleborni with a higher prevalence was reported in Redtail guenons the non-human primates by Gillespie et al. [10] and Strongyloides sp. was documented in omnivores like macaques by Varadharajan and Pythal [8].

In this regard, Nath et al. [11] opined that higher level of parasitism in macaques could be attributed to the presence of abnormally high densities, cross species transmission and stress due to cold temperatures, fighting and varied food habits which exacerbated the occurrence of parasitic infections to the point of even causing death. Encountering the prevalence of Strongyles in the fecal samples obtained from Bonnet macaques furnished by Sharma et al. [12], who encountered the endoparasitic prevalence of 55.42 per cent associated with Strongyles. Similarly, the eggs of Strongyles were encountered along with the coccidial infections in macaques by Varadharajan and Pythal [8], who further stated that the parasitic diseases constituted one of the major problems leading to even mortality in wild animals, under the captivity. Wallach and Boever [5] opined that Trichuris trichiura infection was found to be higher in non-human primates which had direct contact with soil and the embryonated eggs were ingested with food, water or soil. In this regard, it becomes significant to mention the report furnished by Urquhart et al. [13], who opined that one of the important features with Trichuris sp. was the longevity of the eggs. The influence of season as encountered on the parasitic occurrence in non-human primates with the Bonnet macaques during the summer season, pertaining to Ascaris sp. as well as to Trichuris sp. was further supported by Sharma et al. [12], who stated that the pattern of gastrointestinal parasitism might vary from place to place, depending upon the climatic conditions, in addition to the geographic conditions.

\section{Conclusion}

As the outcome of this study the general parasitic prevalence was found out in free ranging Bonnet macaques in Coonoor town, The Nilgiris, and statistically no significant variations were found between the three regions where it was sampled from, the conclusion being that parasitism existed at the same level in all the three regions. The existing parasitism in these urban free ranging macaques also poses a zoonotic threat as these parasites have the ability to attack human beings if they are provided with the suitable factors and also as accidental hosts. The only concern for further critical investigation is that the sharing of the same environment by both the human beings and the macaques also mostly a floating population of tourists, so arising nidus should be well controlled. The intestinal protozoa should also be considered and suitable stains should be used. This will be an opening for future study.

\section{References}

1. Kurup GU (1981) Report on the census survey of rural and urban populations of non-human primates of south India. Man and Biosphere Programme: Project no.124: Zoological Survey of India, Calicut.

2. Pirta RS, Prakash P, Singh M (1981) A population study of two species of non-human primates: Macaca mulatta and Macaca radiata. J Bombay Nat Hist Soc 77: 429-434.

3. Singh M, Akram N, Pirta RS (1984) Evolution of demographic pattern in the Bonnet macaque (Macaca radiata). In: Roonwal ML, Mohnot SM, Rathore NS (eds). Current Primate Researches, Zoology Department, Jodhpur University, Jodhpur, pp: 7-16.

4. Soulsby EJ (1982) Helminths, Arthropods and Protozoa of domestic animals (7th edn.) ELBS, Bareilly Tindall, London.

5. Wallach JD, Boever WJ (1983) Diseases of Exotic Animals- Medical and Surgical Management. W.B. Saunders Company, Tokyo.

6. Fowler ME (1986) Zoo and Wild Animal medicine (2ndedn.) W.B. Saunders Company, Hong Kong.

7. Lim YA, Ngui R, Shukri J, Rohela M, Mat Naim HR (2008) Intestinal parasites in various animals at a zoo in Malaysia. Vet Parasitol 157: 154-159.

8. Varadharajan A, Pythal C (1999) A preliminary investigation of the parasites of wild animals at the zoological Garden. Thiruvananthapuram, Kerala. Zoos's Print Journal 1: 159-164.

9. Raman M, Jayathangaraj MG, John MC, Chellappa DJ (2000) Strongyloidosis in Bonnet macaques in Chennai, India. J Assam vet cou 7-8.

10. Gillespie TR, Chapman CA, Greiner (2005) Effects of logging on gastrointestinal parasite infections and infection risk in African primates. J Appl Ecol 42: 699-707.

11. Nath BC, Islam S, Chakraborty A (2012) Prevalence of parasitic infection in captive non-human primates of Assam State Zoo, India. Veterinary World 5: 614-616.

12. Sharma P, Kumar V, Pal B, Mandial RK, Jithendran KP, et al. (2013) Prevalence of gastrointestinal parasitism in free ranging rhesus macaque (Macaca mulatta) of Himachal Pradesh. Zoo's print 28: 26-27.

13. Urquhart GM, Armour J, Duncan JL, Dunn AM, Jennings FW (1996) Veterinary Parasitology. Longman Scientific and Technical, England. 